\title{
Clinical Trial of Epsilon-aminocaproic Àcid in Severe Haemophilia
}

\author{
A. M. GORDON,* M.B., D.PATH. ; G. P. MCNICOL, $†$ M.D., M.R.C.P.ED., M.R.C.P.GLASG. ; \\ ANNE H. C. DUBBER, $\dagger$ M.B.; G. A. MCDONALD,* M.D., M.C.PATH. ; \\ A. S. DOUGLAS, $\dagger$ M.D., B.SC., F.R.C.P., F.R.C.P.ED., F.R.C.P. GLASG.
}

Brit. med. F., 1965, 1, 1632-1635

This paper reports the results of a clinical trial of the fibrinolytic inhibitor epsilon-aminocaproic acid (E.A.C.A.) in a group of patients with high-grade haemophilia. There is evidence to suggest that the coagulation system and the fibrinolytic enzyme system may be in a state of dynamic equilibrium ; the E.A.C.A. was given in an attempt to displace the balance in favour of haemostasis.

The main components of the fibrinolytic enzyme system are plasminogen, plasmin, activators, and inhibitors. Plasminogen, a naturally occurring plasma globulin, is converted by activators to plasmin, an enzyme which can digest many proteins, including fibrinogen and fibrin, prothrombin, factor $\mathrm{V}$, and antihaemophilic globulin. Under physiological circumstances it is thought that natural inhibitors in the plasma restrict plasmin to digestion of fibrin, but in pathological fibrinolytic (hyperplasminaemic) states plasma proteins, including fibrinogen and antihaemophilic globulin, are digested. Activators of plasminogen include a plasma activator, trace quantities of which are probably responsible for physiological fibrinolytic activity, a urinary activator named urokinase, and activators of bacterial origin-for example, streptokinase. E.A.C.A., a potent competitive inhibitor of plasminogen activation (Alkjaersig et al., 1959), was first used in man by Sherry et al. (1959), who found it effective in inhibiting plasma fibrinolytic activity induced by a variety of plasminogen activators. The value of E.A.C.A. in the treatment of pathological fibrinolytic states has recently been reviewed by $\mathrm{McNicol}$ and Douglas (1964), who also discuss the pharmacology and toxicity of E.A.C.A. E.A.C.A., a synthetic amino-acid which closely resembles lysine in structure, is rapidly absorbed when taken by mouth. Peak plasma levels are found about two hours after a single oral dose. Urinary excretion is also rapid, the greater part of a single dose being recovered unchanged in the urine in 12 hours. The action of E.A.C.A. as an inhibitor of plasminogen activation is seen with plasma concentrations above $1 \mathrm{mg} . / 100 \mathrm{ml}$.

The first report of the use of E.A.C.A. in haemophilia was from McNicol et al. (1961a) who, during a study of the beneficial effect on post-operative haemostasis of E.A.C.A. given to produce local inhibition of urokinase activity in the urinary tract, gave E.A.C.A. to a high-grade haemophiliac with haematuria. The haematuria ceased with E.A.C.A. administration, but at the same time the patient developed renal colic and was found subsequently to have permanent loss of function in one kidney, presumably because of ureteric blockage with unlysable clot. Steiger et al. (1962) and Barkhan (1964) have also reported successful control of haematuria in three patients and one patient respectively with haemophilia, without any adverse effects on renal function. Abe et al. (1962) and Reid et al. (1964) report favourably on the use of E.A.C.A. for other haemorrhagic complications in small numbers of haemophiliacs.

On theoretical grounds there are reasons for considering that E.A.C.A. might have a beneficial systemic effect in the treatment of high-grade haemophilia, in addition to control of local

* University Department of Pathology, Glasgow Royal Infirmary. † University Department of Medicine, Glasgow Royal Infirmary. fibrinolytic activity. It is reasonable to suppose that administration of a potent antifibrinolytic agent might displace the equilibrium of the coagulation-fibrinolytic systems in favour of haemostasis by protecting any clots which form from physiological fibrinolytic processes. Further, E.A.C.A. might conceivably protect plasma coagulation factors, such as factor $\mathrm{V}$ and antihaemophilic globulin (factor VIII), from digestion by low levels of plasmin which may be in part responsible for physiological turnover of these clotting factors. In view of these considerations, and of the favourable reports in the literature, it was thought worth while to embark on a controlled clinical and laboratory study of E.A.C.A. in a group of highgrade haemophiliacs.

\section{Materials and Methods}

\section{Design of the Trial}

Ten haemophiliacs were chosen, each with a history of severe spontaneous bleeding episodes, and with a level of antihaemophilic globulin (factor VIII) of less than $1 \%$, whose ages ranged from 12 to 41 years (with a mean of 20.3 years).

A random allocation of E.A.C.A., dissolved in a syrupy vehicle, and a placebo (vehicle only) was made. The subjects received the active agent (in a dose of $3.3 \mathrm{~g}$. orally four times daily with meals) for six weeks, followed by the placebo preparation (or vice versa) for the same period in identical dosage, with an intervening six-week phase during which no medication was given. The trial was conducted in a double-blind manner, the subsequent clinical observations being made by the same individual throughout. The key to the identity of the preparations was not broken until the conclusion of the trial.

During each phase of six weeks the patients attended twice weekly at an out-patient clinic, and were questioned regarding the occurrence of bleeding episodes. Any haemorrhagic lesions present were assessed clinically and awarded a score ranging from 1 to 4 according to the size and severity of the lesion: the total score for each patient for each of the six-week periods was calculated.

At the beginning of the trial, and at intervals of three weeks thereafter, citrated and heparinized samples of venous blood were collected from each subject for estimation of haemoglobin, white-cell count, platelets, and erythrocyte sedimentation rate, and for liver-function tests. In addition, plasma samples were assayed for antihaemophilic globulin (factor VIIII), plasminogen, and fibrinogen levels. Urokinase-sensitivity tests were performed, and plasma electrophoresis was carried out.

An E.C.G. (standard limb leads) was performed on each patient at the start of the trial and at the termination of each six-week phase.

Plasminogen assays were carried out by the caseinolytic technique of Remmert and Cohen (1949) as modified by Alkjaersig et al. (1959).

Fibrinogen assays were performed by the method of Ratnoff and Menzie (1951) as modified by Alkjaersig (1960). 
Antihaemophilic globulin (factor VIII) assays were performed by a method which is dependent on the clotting-time of recalcified plasma from patients with severe haemophilia, which is maximally "contact activated" by kaolin. Cephalin, prepared as described by Bell and Alton (1954), was added to the substrate system.

Urokinase-sensitivity tests were carried out as described by McNicol et al. (1963). To $0.2 \mathrm{ml}$. of citrated plasma were added $80 \mu$ l. of urokinase solution (500 units $/ \mathrm{ml}$.) and thrombin $(0.1 \mathrm{ml}$. of a $20 \mathrm{~N}$. I.H. unit $/ \mathrm{ml}$. solution). The plasma was incubated at $37^{\circ} \mathrm{C}$., and the times for complete clot lysis were measured. Following the reasoning discussed in the assignment of units to euglobulin lysis times (Sherry and Alkjaersig, 1957), activity in the urokinase-sensitivity test results was expressed in arbitrary units, a lysis time of 10 minutes being assigned 1 unit of activity. The shorter the lysis time induced by urokinase the higher the units of activity-that is, the presence of an inhibitor of activation would be associated with a small number of units of activity.

Urokinase, a purified preparation isolated from the urine of normal males, was made available by Leo Laboratories Ltd.

Epsilon-aminocaproic acid (E.A.C.A.) was supplied by Kabi Pharmaceuticals Ltd., Sweden.

Plasma electrophoresis.-Oxoid cellulose acetate strips were used. These were run for two hours at 150 volts in a Shandon horizontal electrophoresis tank. After staining the strips were scanned in a Chromoscan recording and integrating densitometer, and $\alpha_{1}, \alpha_{2}, \beta$, and $\gamma$ globulins were expressed as a percentage of total plasma protein.

\section{Results}

Table I shows the total bleeding events and cumulative scores recorded for the 10 subjects during each of the three six-week periods of observation. The relative numbers of spontaneous and traumatically induced bleeding episodes are also recorded.

\begin{tabular}{|c|c|c|c|}
\hline Events & $\begin{array}{l}\text { E.A.C.A. for } \\
6 \text { Weeks }\end{array}$ & $\begin{array}{c}\text { Placebo } \\
\text { Preparation } \\
\text { for } 6 \text { Weeks }\end{array}$ & $\begin{array}{l}\text { No Medication } \\
\text { for } 6 \text { Weeks }\end{array}$ \\
\hline 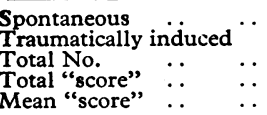 & $\begin{array}{c}12 \\
22 \\
34 \\
69 \\
6 \cdot 9 \pm 2 \cdot 6\end{array}$ & $\begin{array}{c}24 \\
30 \\
54 \\
101 \\
10 \cdot 1 \pm 5 \cdot 0\end{array}$ & $\begin{array}{c}19 \\
24 \\
43 \\
90 \\
9 \cdot 0 \pm 4 \cdot 7\end{array}$ \\
\hline
\end{tabular}

The observed differences of the scores between E.A.C.A. and placebo periods just fail to achieve the conventionally accepted level of statistical significance $(t=2.137$ and $0.5>P>0.1$; $t=2.262$ would give $P<0.05$ ), but it is of interest to note that the number of spontaneous bleeding espisodes recorded during the period of E.A.C.A. administration is only half the number occurring during the placebo phase.

Fig. 1 shows the total scores for each patient while on E.A.C.A., no medication, and placebo. The intermediate score recorded with no medication may in part be due to excretion of E.A.C.A. during the first 10-14 days of the no-medication period from the body pool with which it had equilibrated in those patients who were given E.A.C.A. before placebo. Fig. 2 shows the changes in score noted between E.A.C.A. and placebo phases of the trial. It will be seen that only one subject gave a higher score on E.A.C.A. than on placebo.

Table II shows an analysis of the nature of the haemorrhagic episodes during each of the trial periods. The number of haemarthroses recorded during the placebo period is more than twice that recorded during the period of E.A.C.A. ingestion.

\begin{tabular}{l} 
TABLE II.-Analysis of Haemorrhagic Events Occurring During the \\
Trial of E.A.C.A. in 10 Patients with Haemophilia \\
\hline \multicolumn{2}{c|}{ Event } \\
\hline
\end{tabular}

Table III gives the results of clotting and lytic factor assays during the trial. E.A.C.A. had no effect upon the level of antihaemophilic globulin (factor VIII) in any of the subjects

TABLE III.-Results of Assay of Clotting and Lytic Factors (10 Subjects). Results are Expressed as Mean Values and Standard Deviation

\begin{tabular}{|c|c|c|c|c|}
\hline Estimations & $\begin{array}{c}\text { At } \\
\text { Beginning } \\
\text { of Trial }\end{array}$ & $\begin{array}{l}\text { After } 6 \\
\text { Weeks of } \\
\text { E.A.C.A. }\end{array}$ & $\begin{array}{c}\text { After } 6 \\
\text { Weeks } \\
\text { of No } \\
\text { Medication }\end{array}$ & $\begin{array}{c}\text { After } 6 \\
\text { Weeks of } \\
\text { Placebo } \\
\text { Preparation }\end{array}$ \\
\hline $\begin{array}{l}\text { Antihaemophilic globulin } \\
\text { (factor VIII) } \\
\text { Plasminogen (casein units/ } \\
\text { ml.) } \\
\text { Fibrinogen (mg./100 mi.) } \\
\text { Urokinase sensitivity } \\
\text { (units)* } \\
\text { (un }\end{array}$ & $\begin{array}{c}\text { All }<1 \% \\
2 \cdot 4 \pm 0.6 \\
387 \pm 149 \\
1 \cdot 13 \pm 0.52\end{array}$ & $\begin{array}{l}\text { All }<1 \% \\
2.1 \pm 0.76 \\
288 \pm 103 \\
0.16 \pm 0.1\end{array}$ & $\begin{array}{c}\text { All }<1 \% \\
2.3 \pm 0.7 \\
267 \pm 98 \\
1.06 \pm 0.39\end{array}$ & $\begin{aligned} \text { All } & <1 \% \\
2.5 & \pm 1.0 \\
336 & \pm 171 \\
0.92 & \pm 0.27\end{aligned}$ \\
\hline
\end{tabular}

studied. The consistently low results in the urokinasesensitivity tests while the patients were given E.A.C.A. indicated that these patients were reliable in taking the medication, which had imparted a marked resistance to urokinase in every sample tested during the E.A.C.A. phase of the trial.

The mean values for plasminogen and fibrinogen are not significantly different during the period of E.A.C.A. and placebo treatment, while standard haematological values and parameters of liver function (recorded in Table IV) give no indication of marrow or liver dysfunction attributable to E.A.C.A.

E.A.C.A. Fig. 3 shows the relation between plasma fibrinogen levels and E.S.R. estimations for all the samples taken off during the trial. A strong positive correlation between elevation of fibrinogen and elevation of E.S.R. was found $(P<0.001)$. Wide individual fluctuations in fibrinogen levels and E.S.R. were noted during the trial, the levels rising in association with haemorrhagic episodes.

No E.C.G. abnormalities were recorded during E.A.C.A. therapy. Side-effects were minimal. One patient reported nasal stuffiness, while another complained of mild diarrhoea and abdominal discomfort during E.A.C.A. administration. No thrombotic episodes were recorded in any of the subjects.
FIG. 1.-Frequency distribution of numerical scores awarded for bleeding episodes occurring during the clinical trial of E.A.C.A. in 10 patents with severe haemophilia. Results are shown for the six-week period on E.A.C.A., six weeks on placebo, and six weeks without medication. FIG. 2.- Change in score recorded for each subiect for the period of E.A.C.A. compared with the period on placebo. 


\section{Discussion}

The clinical results obtained during the present trial do not permit definite conclusions regarding the values of E.A.C.A. in haemophilia, since the difference of the "scores" recorded during the phases of ingestion of active and placebo preparations do not quite achieve the conventionally accepted level of statistical significance. Nevertheless, the reduced number of spontaneous bleeding episodes and the relatively small number of haemarthroses seen during the E.A.C.A. test period are quite impressive. We consider that the overall pattern of results is encouraging enough to warrant large-scale study of E.A.C.A. in a further group of haemophiliacs, and that E.A.C.A. may have definite values as a prophylactic agent in high-grade haemophilia.

The consistent failure of E.A.C.A. to cause a rise in plasma levels of antihaemophilic globulin (factor VIII) suggests that physiological levels of plasma fibrinolytic activity are not responsible for destruction of antihaemophilic globulin in vivo in high-grade haemophiliacs, and the improvement in haemostasis seen in the present trial cannot be attributed to protection of antihaemophilic globulin from proteolysis by plasmin. Further, the failure to see a rise in plasma fibrinogen levels suggests that plasma fibrinogen turnover is not mediated through plasma fibrinolytic activity. Moreover, Rausen et al. (1961), using fibrinogen labelled with radioactive iodine, have shown that fibrinogen turnover is normal in patients with severe haemophilia, suggesting that in vivo clotting is not a major factor in the fibrinogen turnover ; and it would therefore appear that turnover of fibrinogen is produced by some biochemical mechanism other than digestion by plasmin or intravascular clotting.

TABle IV.-Results Expressed as Mean Values and Standard Deviation of Haematological and Biochemical Tests Performed During the Trial of E.A.C.A. in Patients with High-grade Haemophilia. $(\alpha, \alpha$ $\beta, \gamma$ Globulins are Expressed as Percentages of Total Plasma Proteins)

\begin{tabular}{|c|c|c|c|c|}
\hline Estir & $\underset{\text { Beginning }}{\text { of Trial }}$ & $\begin{array}{l}\text { After } 6 \\
\text { Weeks of } \\
\text { E.A.C.A. }\end{array}$ & $\begin{array}{c}\text { After 6 } \\
\text { Weeks } \\
\text { of No } \\
\text { Medication }\end{array}$ & $\begin{array}{c}\text { After } 6 \\
\text { Weeks of } \\
\text { Placebo } \\
\text { Preparation }\end{array}$ \\
\hline $\begin{array}{l}\times 10 \\
10^{5} / \mathrm{c} \\
\text { in } 1\end{array}$ & $\begin{aligned} 13.1 \pm & 1.4 \\
6.3 \pm & 1.1 \\
2.6 \pm & 0.5\end{aligned}$ & $\begin{aligned} & 13.2 \pm 1.6 \\
& 6.5 \pm 11.2 \\
& 2.6 \pm 0.6\end{aligned}$ & $\begin{aligned} 12.8 \pm & 1.7 \\
6.7 \pm & 1.5 \\
2.5 \pm & 0.9\end{aligned}$ & 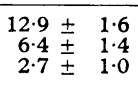 \\
\hline e & $13 \cdot 8$ & $10 \cdot 6 \pm 11 \cdot 1$ & $9 \cdot 3 \pm 9 \cdot 1$ & $21 \cdot 4 \pm 20 \cdot 8$ \\
\hline & $12 \cdot 9=$ & $12 \cdot 2 \pm 5 \cdot 2$ & $10 \cdot 3 \pm 3.9$ & $10 \cdot 8 \pm 3 \cdot 1$ \\
\hline (g. $/ 100$ & $\begin{array}{ll}0.4 & \pm \cdot 2 \\
1 \cdot 0 & 0.5 \\
0.5\end{array}$ & $\begin{array}{l}0.4 \pm 0.1 \\
0.6 \pm 0.9\end{array}$ & $\begin{array}{ll}0.5 \pm & 0.3 \\
0.9 & 0.4\end{array}$ & $\begin{array}{l}0.4 \pm 0.2 \\
0.9 \pm 0.2\end{array}$ \\
\hline $\begin{array}{l}\mathrm{ml} \text { ) } \\
\text { Total globulins }\end{array}$ & 0.3 & $3.9 \pm 0.4$ & $1 \pm 0.6$ & $3.8 \pm 0.4$ \\
\hline $\begin{array}{l}\text { ml.) } \\
\alpha_{1} \text {-Globulin (\%) } \\
a_{2} \text {-Globulin (\%) } \\
\beta \text {-Globulin }(\%) \\
\gamma \text {-Globulin }(\%)\end{array}$ & $\begin{aligned} 3.1 \pm & 0.5 \\
4.2 \pm & 1.2 \\
11.3 \pm & 4.3 \\
20.7 \pm & 4 \cdot 2 \\
16.8 \pm & 5.2\end{aligned}$ & $\begin{aligned} 2.9 \pm & 0.5 \\
4.0 \pm & 1.5 \\
11.8 \pm & 7.7 \\
20.1 \pm & 6.7 \\
15.6 \pm & 3.9\end{aligned}$ & $\begin{array}{rl}3.3 \pm & 0.7 \\
3.9 \pm & 1.6 \\
11.6 \pm & 5.3 \\
18.6 & 5.8 \\
15.1 \pm \pm & 3.4\end{array}$ & $\begin{aligned} 3.0 \pm & 0.5 \\
4.5 \pm & 2.0 \\
12.8 \pm & 3.9 \\
19.4 \pm & 5.0 \\
16.6 \pm & 5.9\end{aligned}$ \\
\hline
\end{tabular}

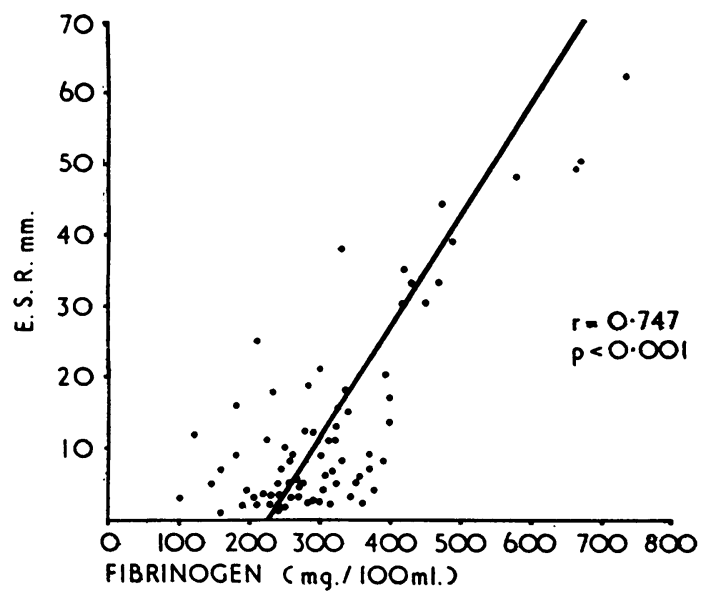
FIG. 3.- Relation between fibrinogen and E.S.R. levels
observed during the trial. $(\mathrm{X}=6.4 \mathrm{Y}+226$.
No direct estimation of plasma E.A.C.A. levels was made, but as measured by the resistance of the plasma to lysis by urokinase in the urokinase-sensitivity test, marked antifibrinolytic activity was imparted to the plasma by the dosage schedule of E.A.C.A. which was employed in the trial. From previous studies (McNicol et al., 1962) the dosage employed in the present trial, $3.3 \mathrm{~g}$. six-hourly, might have been expected to achieve plasma E.A.C.A. levels fluctuating between 2 and $10 \mathrm{mg}$. $/ 100 \mathrm{ml}$., levels adequate to produce inhibition of plasma plasminogen activation varying from detectable at the lower levels to marked at the upper levels.

\section{Toxicity and Side-effects of E.A.C.A.}

With regard to the fundamental action of E.A.C.A. upon the plasminogen-plasmin system, and the accepted role of the latter in maintaining a patent vascular tree, the possibility exists that E.A.C.A. might cause vascular occlusion by inhibiting the lysis of intravascular fibrin. This potential hazard has been the subject of several published reports. Andersson et al. (1962) found that in a trial of 50 patients given E.A.C.A. following prostatectomy 9 had evidence of thrombosis or embolism, and that 5 out of 25 control patients also had post-operative thromboembolic complications. McNicol et al. (1961b), in a trial of E.A.C.A. given to 23 patients after prostatectomy, noted vascular occlusion in two patients some hours after administration of E.A.C.A. in one patient and 10 days later in the other. There are other reports of vascular occlusion following E.A.C.A. therapy from Naeye (1962) and Fletcher et al. (1962a). In the present trial, as might be anticipated in patients with grossly deficient haemostatic mechanisms, there was no clinical evidence of the occurrence of vascular occlusive episodes at any time in any of the subjects during E.A.C.A. therapy.

The serial haematological and biochemical estimations performed during the trial gave no evidence of marrow depression or liver dysfunction attributable to E.A.C.A.

Reported side-effects of E.A.C.A. have included hypotension and dizziness (Andersson et al., 1962 ; Beck et al., 1963), abdominal discomfort, conjunctival suffusion, and nasal stuffiness (McNicol et al., 1962).

In the present study only two patients experienced abnormal symptoms that might possibly be attributed to E.A.C.A. One subject complained of nasal congestion and headache, while a second experienced several episodes of mild diarrhoea and abdominal discomfort. In neither case were symptoms sufficiently incapacitating to require withdrawal of the drug.

As has been reported by McNicol et al. (1962), E.A.C.A., in the isolated rat-diaphragm preparation, inhibits the incorporation into protein of lysine, which it structurally resembles, and it is possible, especially in growing children, that long-term administration of E.A.C.A. might have deleterious effects, not seen in the present trial, due to interference in this or other ways with amino-acid metabolism. Accordingly, the much more potent (Dubber et al., 1964) and in animal studies less toxic (Melander et al., 1964) fibrinolytic inhibitor aminomethyl cyclohexane carboxylic acid (A.M.C.A.), which is not at present commercially available, may prove to be the agent of choice for long-term use.

\section{Summary}

The results of a controlled clinical trial of epsilon-aminocaproic acid (E.A.C.A.) on 10 high-grade haemophiliacs are described.

Although the total "scores" assigned to haemorrhagic events was lower during a six-week period of E.A.C.A. therapy than in corresponding six-week phases of placebo medication and no medication respectively, the observed differences do not quite achieve the conventionally accepted level of statistical significance. 
An appreciable reduction of spontaneous bleeding episodes was recorded during the administration of E.A.C.A.

No rise in antihaemophilic globulin (factor VIII) was demonstrated in any of the patients during E.A.C.A. therapy, nor were any significant changes observed in plasminogen and fibrinogen levels, or plasma $\alpha_{1}, \alpha_{2}, \beta$, or $\gamma$ globulins.

No abnormalities of marrow or liver function were detected during E.A.C.A. administration.

It is considered that the results warrant further large-scale study of E.A.C.A. at the clinical level in haemophilia, and the view is expressed that the drug or another fibrinolytic inhibitor -for example, the more potent aminoacid, aminomethyl cyclohexane carboxylic acid-may be of prophylactic value in the clinical management of high-grade haemophilia.

E.A.C.A. and placebo syrups were kindly provided by Dr. Hans Dahlström, of Kabi Pharmaceuticals. We are grateful to Dr. J. H. Wright for electrocardiography; to Dr. J. C. Eaton for liverfunction tests; and to Miss B. C. Bayley for technical help. The Medical Research Council provided financial support.

\section{BIBLIOGRAPHY}

Abe, T., Sato, A., Kazama, M., and Matsumura, T. (1962). Lancet, 2, 405 .

Ablondi, F. B., Hagan, J. J., Philips, M., and de Renzo, E. C. (1959). Arch. Biochem., 82, 153 .

Alkjaersig, N. (1960). In N.I.H. Conference on Thrombolytic Agents, edted by H. R. Roberts and D. Geraty, p. 316. Chapel Hill. - Fletcher, A. P., and Sherry, S. (1959). F. biol. Chem., 234, 832.
Andersson, L., and Nilsson, I. M. (1961). Acta chir. scand., 121, 291. and Olow, B. (1962). Thrombos. Diathes. haemorrh. (Stuttg.), 7, 391.

Astrup, T. (1956). Lancet, 2, 565.

Barkhan, P. (1964). Ibid., 2, 1061

Beck, E., Schmutzler, R., and Duckert, F. (1963). Thrombos. Diathes. haemorrh. (Stuttg.), 10, 106.

Bell, W. N., and Alton, H. G. (1954). Nature (Lond.), 174, 880.

Dubber, Anne H. C., McNicol, G. P., Douglas, A. S., and Melander, B. (1964). Lancet, 2, 1317.

Fletcher, A. P., Alkjaersig, N., and Sherry, S. (1962a). Amer. Y. Med., 33, 738 .

Gans,

Gans, H., and Krivit, W. (1962). Ann. Surg., 155, 268.

Grossi, C. E., Moreno, A. H., and Rousselot, L. M. (1961). Ibld., 153, 383.

Johnson, A. J., Skoza, L., and Claus, E. (1962). Thrombos. Diathes. haemorrh. (Stuttg.), 7, 203 (Abstract).

McNicol, G. P., and Douglas, A. S. (1964). Brit. med. Bull., 20, 233.

Fletcher, A. P., Alkjaersig, N., and Sherry, S. (1961a). \%. Urol. (Baltimore), 86, 829.

_ - (1961b). F. Lab. clin. Med., 58, 34.

Z $=$ (1962). Ibid., 59, 15 .

- Gale, S. B., and Douglas, A. S. (1963). Brit. med. 7., 1, 909.

Melander, B., Gliniecki, E., Granstraud, B., and Hanshoff, G. (1964). Proceedings of Xth Congress of the International Society of Haematology, Stockholm, 30 August to 4 September.

Mikata, I., Hasegawa, M., Igarashi, T., Shirakura, N., Hoshida, M., and Toyama, K. (1959). Keio 7. Med., 8, 279.

Naeye, R. L. (1962). Blood, 19, 694.

Nolf, P. (1908). Arch. int. Physiol., 6, 306.

Ratnoff, O. D., and Menzie, C. (1951). 7. Lab. clin. Med., 37, 316.

Rausen, A. R., Cruchaud, A., McMillan, C. W., and Gitlin, D. (1961). Blood, 18, 710 .

Reid, W. O., Lucas, O. N., Francisco, J., Geisler, P. H., and Ensler, A. J. (1964). Amer. Ұ.' med. Sci., 248, 184.

Remmert, L. F., and Cohen, P. P. (1949). Y. biol. Chem., 181, 431.

Sherry, S., and Alkjaersig, N. (1957). Thrombos. Diathes. haemorrh. (Stuttg.), 1, 264.

Fletcher, A. P., and Alkjaersig, N. (1959). Physiol. Rev., 39, 343.

Steiger, B., White, J. G., and Krivit, W. (1962) 7. Lancet, 82, 421.

\title{
A Comparison of the Mortality from Bronchitis in Scotland and in England and Wales
}

\author{
EILEEN C. CROFTON,* B.M., B.CH.
}

Chronic bronchitis is an ill-defined disease which may not always have been accurately diagnosed as a cause of death. It is liable to be associated with other diseases of a chronic degenerative type, and the final diagnosis of cause of death may be a matter of individual choice and regional variation. The purpose of this inquiry was to ascertain to what extent there is a genuine difference in the mortality from chronic bronchitis in Scotland and in England and Wales, and to find, if any such difference exists, whether reasons could be given in explanation.

The death rates from bronchitis in Scotland and in England and Wales over the years 1940 to 1960 inclusive were standardized for age against a standard population, that of the combined population of Scotland and England and Wales obtained in the 1951 census. This procedure eliminates any bias due to a difference in age structure of the two populations. The results for males and females separately are shown in Fig. 1, A and B. According to these figures there is a marked preponderance of mortality in England and Wales compared with Scotland, which amounts to an average excess of $28.5 \%$ in the males and $23.6 \%$ in the females. In England and Wales, after the high values in 1940 and 1941, the death rate

\footnotetext{
- Honorary Research Assistant, Department of Respiratory Diseases and Tuberculosis, University of Edinburgh.
}

in males has been fairly steady apart from the sharp increase in 1951 associated with the influenza epidemic in the first two months of the year. Scotland, on the other hand, at its lower level, has shown a tendency for the rate to rise in the last six or seven years, the rate now approximating to that for England and Wales. The females show a steady decline in mortality over the 21-year period in both countries, but the decline has slowed down in Scotland in recent years.

\section{Death Rates Related to Degree of Urbanization}

The lower rates in Scotland might be due to the larger proportion of the population living under rural or semi-rural conditions. In fact the difference in urbanization between the two countries is not as great as might be expected, owing to the concentration of population in Scotland in the Forth-Clyde industrial belt. In Scotland in 1959, $45.8 \%$ of the population lived in small burghs (towns) or landward (rural) areas. In the same year in England and Wales the proportion was $40.6 \%$. $A$ priori it seems unlikely that a difference of $5.2 \%$ could entirely account for the large difference in the bronchitls mortality rates, but this possibility has been examined.

The mortality rates in the different parts of the two countries were compared, following the Registrar-Generals' 